\title{
Comentario sobre el proyecto de modificación del código penal en relación a las medidas de seguridad. Grupo de "etica y legislación”" Asociación Española de Neuropsiquiatría (AEN).
}

Comment on the project of modification of the penal code in relation to the safety measures. Work group on "ethics and legislation", Spanish Association of Neuropsychiatry (AEN).

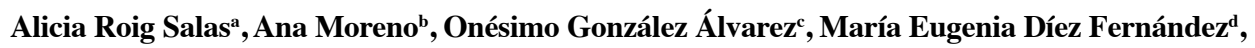
Mariano Hernández Monsalve ${ }^{\mathrm{e}}$, José Leal Rubio ${ }^{\mathrm{f}}$, Fernando Santos Urbaneja ${ }^{\mathrm{g}}$.

${ }^{a}$ Psiquiatra, Barcelona, España. ${ }^{b}$ Psiquiatra, Alcalá de Henares, Madrid, España. ${ }^{c}$ Psiquiatra, Huelva, España. ${ }^{d}$ Psicóloga Clínica, Asturias, España. ${ }^{e}$ Psiquiatra, Madrid, España.${ }^{f}$ Psicologo Clínico, Barcelona, España. ${ }^{g}$ Jurista, Córdoba, España.
\end{abstract}

\begin{abstract}
RESUMEN: El proyecto de modificación del Código Penal que propone el Gobierno introduce elementos que pueden ser seriamente lesivos para los derechos y libertades de las personas que padecen algún trastorno mental. El presente documento hace un análisis de dicho proyecto en lo que se refiere especialmente a las medidas de seguridad, propone una serie de enmiendas y fija la posición de la AEN en este tema.
\end{abstract}

ABSTRACT: The project of modification of the Penal Code that the Government proposes introduces elements that can be seriously harmful for the rights and freedoms of the persons who suffer some mental disorder. The present document does an analysis of the above mentioned project in what it refers specially to the safety measures, proposes a series of amendments and fixes the position of the AEN in this topic.

\section{1.- INTRODUCCIÓN}

El pasado mes de Marzo se elaboró y publicó el informe de la Asociación Española de Neuropsiquiatría (AEN) sobre el texto del "Anteproyecto" de modificación del Código Penal.

En dicho informe se hacía una crítica muy severa al conjunto del articulado propuesto en materia de "Medidas de Seguridad", aplicable a personas con trastorno mental o discapacidad intelectual.

Es preciso reconocer que el Proyecto que ahora vamos a analizar, elimina alguno de los aspectos más negativos que contenía el Anteproyecto, como la medida de "custodia de seguridad" y somete a mayores garantías de contradicción decisiones tan trascendentes y, en nuestra opinión, discriminatorias, como la posibilidad de prorrogar el internamiento por periodos sucesivos de cinco años (Art. 98-3 II)

Pero, más allá de esto, el Proyecto mantiene la misma concepción discriminatoria y excluyente en relación con las personas con trastorno mental o discapacidad intelectual. 
INFORMES

El Proyecto de Reforma del Código Penal forma parte de un conjunto de medidas legislativas destinadas a la sustitución apresurada de nuestro precario estado de bienestar por un "estado caritativo" que culminará en un "estado penal", proceso en el que las políticas sociales están siendo progresivamente sustituidas por políticas de vigilancia y control, que incluye la "contención punitiva" de las categorías sociales más desfavorecidas.

Resulta muy grave la mutación de un "derecho penal del hecho" en "derecho penal de autor"

La peligrosidad no es un concepto clínico ni psicopatológico. No hay fundamento científico para que los profesionales de la salud mental puedan evaluar la presunta peligrosidad de la persona.

El derecho penal del hecho exige contextualizar las conductas, analizar el hecho delictivo en sus circunstancias y extraer de tal análisis los motivos y las eventuales consecuencias.

El derecho penal de autor permite descontextualizar las conductas, vinculándolas a las características personales del sujeto. El trastorno mental vuelve desde el campo sanitario al jurídico-penal, ya que, antes que enfermedad, es vuelto a considerar peligro ó amenaza.

En este punto cabe recordar:

* La precariedad y provisionalidad de la mayor parte del cuerpo teórico de la psiquiatría, así como las escasas validez y fiabilidad de los diagnósticos.

* La posibilidad de que los enfermos mentales cometan un delito no difiere de los llamados normales.

* Los delitos menores de enfermos mentales que viven en la comunidad no dependen de la enfermedad en sí, sino de sus condiciones de vida.

* No hay un solo dato clínico en que apoyar las detenciones preventivas de personas "peligrosas", al margen de consideraciones jurídicas.

* Cuando se asocian conducta delictiva y trastorno mental, la respuesta social se funda más en el desconcierto y en los prejuicios que en la evidencia.

* Es inadmisible la inseguridad jurídica a que vuelven las personas con una enfermedad mental, tanto por la posibilidad de encierro preventivo, predelictual, privación de la libertad fundada en suposiciones, como por la indeterminación de las medidas de seguridad, tanto en su duración como en su naturaleza. Este extremo ha sido criticado unánimemente por la doctrina científica así como por el Consejo General del Poder Judicial.

* Esta legislación entra en confrontación manifiesta con el espíritu y contenido de la Convención de la ONU sobre Derechos de las Personas con Discapacidad de 2006, ratificada por España en el año 2008. 
INFORMES

\section{2. - EL CENTRO DE LA PRETENDIDA REFORMA}

El hecho de que, el de las Medidas de Seguridad, sea el ámbito más profundamente reformado, da idea de la pretensión nuclear de la reforma, cual es incidir de modo severo en el factor "seguridad", en detrimento notable del factor "reinserción y rehabilitación social" (Art. 25 C.E.)

Se insiste un ay otra vez en el concepto de "peligrosidad" que, huérfano en muchos casos de concreciones objetivas, estaría llamado a convertirse en un juicio de valor alimentado por pre-juicios, lo que sitúa la cuestión en términos pre-Constitucionales.

Esto resulta especialmente grave para las personas con trastorno mental.

En el ámbito judicial pervive, quizás más que en cualquier otro, la presencia del "estigma".

No hablamos de oídas, sino desde la experiencia.

A lo largo de la historia nuestros Códigos Penales se han centrado en "categorizar" sin tener en cuenta los contextos sociales y biográficos de la persona.

Por otro lado, hasta que el Código Penal de 1995 estableció una limitación objetiva a la duración de las medidas de seguridad (en atención a la pena establecida para el delito cometido), las personas con trastorno mental a las que se imponía la medida de seguridad de internamiento, permanecían indefinidamente privadas de libertad, en ocasiones en virtud de la comisión de pequeños delitos. Esta situación fue severamente denunciada por la Comisión de Legislación de la Asociación Española de Neuropsiquiatría (AEN) en diversos documentos, así como por el Defensor del Pueblo en su célebre informe de 1991 "Sobre la situación jurídica y asistencial del enfermo mental en España".

Ahora, con la pretendida reforma, se corre el riesgo de que tales situaciones se reproduzcan.

\section{3.- ¿POR QUÉ ESTA REFORMA? ¿POR QUÉ AHORA?}

Suele decirse que "cuando la sociedad cambia, cambia el Derecho".

El Código Penal de 1995 (L.O. 10/1995 de 23 de Noviembre) estableció un sistema de respuesta a los hechos delictivos, basado en la dualidad "penas" y/o "medidas de seguridad", según se apreciase la imputabilidad o inimputabilidad del sujeto.

De acuerdo con el sistema "vicarial", en caso de imposición conjunta de penas y medidas (supuestos de imputabilidad disminuida), éstas deben ser cumplidas en primer lugar, quedando el cumplimiento de las penas supeditado al resultado (buen fin o mal fin) del cumplimiento de las medidas (Art. 99 C. Penal) 
INFORMES

Por otro lado, resultó muy elocuente la redacción del Art. 60 C. Penal, aplicable a los casos de enajenación "inadvertida" o "sobrevenida".

Decía así:

1. Cuando, después de pronunciada sentencia firme, se aprecie en el penado una situación duradera de trastorno mental grave que le impida conocer el sentido de la pena, el Juez de Vigilancia Penitenciaria suspenderá la ejecución de la pena privativa de libertad que se le hubiera impuesto, garantizando que reciba la asistencia médica precisa...

Este precepto representó una admirable ruptura con el sistema que venía aplicándose hasta esa fecha.

La Consulta 5/1999 de la Fiscalía General del Estado sobre "Problemas que plantea el internamiento de quienes tienen suspendida la ejecución de una pena privativa de libertad por trastorno mental grave sobrevenido a la sentencia firme" se hace eco de la novedad en los siguientes términos:

"Si el juicio que demanda el art. 60 del C. Penal no es juicio de peligrosidad, sino juicio de capacidad de comprensión del sentido y alcance de la pena que sufre, es indudable que sobre ese juicio no se puede sustentar la imposición de una medida de seguridad que venga a sustituir a la pena suspendida.

El auto resolutorio del incidente de suspensión de la ejecución no constituye una decisión jurisdiccional apta para acordar la imposición de medidas de seguridad. Como ha manifestado en varias ocasiones la jurisprudencia del Tribunal Supremo y se recordó en la Consulta $\mathrm{n}^{\circ} 1 / 1989$, la medida de seguridad sólo se puede imponer en la sentencia que pone fin al proceso penal tras analizar el fondo de la cuestión relativa a la imputabilidad del acusado en relación con el hecho criminal que se le imputa....

No es admisible por lo tanto que, comprobada la situación de trastorno mental grave del reo y su imposibilidad sobrevenida para conocer el sentido de la pena, el juez o tribunal sentenciador sustituya la pena de prisión por una medida de seguridad de internamiento ni de cualquier otra naturaleza.

Los señores fiscales demandarán en estos casos la suspensión de la ejecución de la pena y el cese efectivo de toda intervención penal, porque la mención que se contiene en el Art. 60 del Código Penal a la obligación que pesa sobre el juez o tribunal de garantizar al penado la asistencia médica, tiene un sentido exclusivamente asistencial y tuitivo de su persona, absolutamente extraño a cualquier medida institucional de reacción penal". 
INFORMES

Decimos "representó", porque la reforma del Código Penal de 2003 (L.O. 15/2003 de 25 de Noviembre) dio una nueva redacción del párrafo primero del Art. 60 del C. Penal, reorientando en cierto modo las cosas a la situación precedente, en la medida en que vuelve a conectar "el recibir asistencia sanitaria precisa" con "la imposición de medidas de seguridad"

En los siguientes términos:

1. Cuando, después de pronunciada sentencia firme, se aprecie en el penado una situación duradera de trastorno mental grave que le impida conocer el sentido de la pena, el Juez de Vigilancia Penitenciaria suspenderá la ejecución de la pena privativa de libertad que se le hubiera impuesto, garantizando que reciba la asistencia médica precisa...

“....para lo cual podrá decretar la imposición de una medida de seguridad privativa de libertad de las previstas en este Código que no podrá ser, en ningún caso, más gravosa que la pena sustituida. Si se tratase de una pena de distinta naturaleza, el Juez de Vigilancia Penitenciaria apreciará si la situación del penado le permite conocer el sentido de la pena y, en su caso, suspenderá la ejecución imponiendo las medidas de seguridad que estime necesarias.

No obstante, las preguntas fundamentales son las siguientes:

¿Por qué esta reforma? ¿Por qué ahora?

¿Tanto ha cambiado la sociedad española desde el año 1995 hasta el año 2013, como para pasar de un sistema penal dirigido fundamentalmente a la rehabilitación y reinserción social, a un sistema que busca decididamente la exclusión y permanente privación de libertad de quienes, a su parecer, merecen la calificación de "peligrosos"?

No parece advertirse tal cambio. Si, como creemos, no se advierte en la ciudadanía un cambio de actitud en relación con la situación del año 1995 tendremos que concluir que se trata de un cambio fundamentalmente "ideológico" que pretende utilizar el Derecho como lo que nunca debe ser, "instrumento de dominio" de un grupo sobre otro/s a los que se percibe como "peligrosos".

Es el caso del colectivo de personas con trastorno mental grave, sin más fundamento que un atávico prejuicio de peligrosidad sin base científica ni estadística.

Porque, ¿Qué delitos cometen estas personas?

Por lo común se tiende a pensar que las personas con enfermedad mental cometen muchos delitos y muy graves.

Ya se ha argumentado al respecto en cuanto a la "cantidad" de infracciones cometidas, muy por debajo de la que la conciencia social les atribuye.

En cuanto a los "delitos" cometidos, el 90\% de las infracciones tienen que ver con incidentes que se producen en los ámbitos donde estas personas habitan, esto es, bien en el domicilio familiar, bien en la calle. 
INFORMES

Es un hecho que las personas con trastorno mental grave se encuentran en muchos casos y por distintas razones, "infratratadas" e "infraatendidas" desde el punto de vista sociosanitario.

En algunos hogares, los familiares de los enfermos se ven obligados a soportar tensiones que les ponen al límite de sus fuerzas y de su resistencia física y emocional.

En este contexto se producen "altercados" familiares que cursan con agitación, violencia verbal, etc... que, desde la reforma del Código Penal de 2003, pasaron de la consideración de simple "falta" a la de "delito" , enmarcados en los denominados "delitos de violencia doméstica o familiar" (Art. 153 C. Penal)

Por otro lado, cuando estas personas se encuentran en la calle (en ocasiones viviendo en ella) a veces con la conciencia de la realidad completamente perdida, protagonizan comportamientos extraños o producen molestias que dan lugar a llamadas de solicitando la presencia policial.

La intervención policial, salvo en aquellos casos en los que los Agentes advierten desde el primer momento que se trata de un enfermo y su actuación se dirige a prestarle auxilio y asistencia médica, suele dar lugar a "altercados" y a la incoación de procedimientos por atentando, amenazas, desobediencia, etc..., a los Agentes de la Autoridad.

En el $90 \%$ de los casos, estos son los "delitos" que cometen estas personas y que, con la legislación actual y mucho más aún con la proyectada, pueden dar lugar a su "anulación personal" por resultar ya casi imposible salir del laberinto que le tiene preparada la nueva legislación penal.

Lo más grave es que todo esto es perfectamente evitable. Muchas de estas situaciones se pueden prevenir mediante una adecuada red de servicios sociosanitarios (algunos previstos ya en la Ley General de Sanidad de 1986), rehabilitadores, laborales, de alojamiento: pisos atendidos, mini-residencias que puedan permitir en los casos necesarios que el usuario pueda vivir fuera del núcleo familiar, y con mayor autonomía.

Señalar también la importancia de que todas estas necesidades puedan incluirse en un eficiente y real "Plan Integral de Salud Mental territorial" que provea además de una atención domiciliaria, accesible y eficaz, demanda ésta también de las Asociaciones de Familiares que compartimos plenamente.

Suplir las carencias del sistema sanitario con actuaciones judiciales, no solo no arregla el problema, sino que criminaliza la enfermedad.

Sigue doliendo mucho la triste afirmación de $\mathrm{D}^{\mathrm{a}}$. Mercedes Gallizo, que fue Directora General de Instituciones Penitenciarias, en la Introducción al "Estudio sobre Salud Mental en el Medio Penitenciario" (Diciembre 2006).

"En ocasiones la prisión se utiliza como un recurso de carácter asistencial para estas personas que no han sido tratadas y controladas en su vida en libertad. 
INFORMES

En este sentido, la prisión constituye muchas veces la única alternativa realmente disponible ante las deficiencias de las políticas preventivas o de los dispositivos asistenciales comunitarios que, en general, deberían ser los utilizados como primera elección"

Resulta profundamente injusto que el propio Estado que tiene el deber de garantizar el derecho a la salud de sus ciudadanos (Art. 43 C.E) y cuya tradicional inhibición en esta materia provoca que los familiares, los vecinos, etc... de las personas enfermas tengan que asumir cargas muchas veces insoportables, cuando la situación se desborda, no tenga otro recurso que acudir a la intervención penal y a la cárcel.

El grado máximo de "sinrazón" se produce cuando las sentencias, por imperativo legal (Art. 48-2 C. Penal), tienen que imponer entre el enfermo y sus familiares, una orden de alejamiento, que éstos en modo alguno han pedido ni desean, solo que su familiar sea tratado adecuadamente desde el punto de vista sanitario, no que ingrese en prisión ni, mucho menos que les impidan además el consuelo de sus visitas y/o de la comunicación telefónica.

\section{4 - LA CUESTIÓN DE LOS MEDIOS}

Es este un aspecto que se omite generalmente en las reformas y en el que no suele repararse pues "se da por hecho" que los medios existen.

De este modo, los Parlamentarios argumentan como si así fuera y los estudiosos de las cátedras no descienden a estos detalles, sin imaginarse siquiera la limitación de medios personales y materiales con que cuenta la Administración de Justicia.

Ocurre, además, que no se trata de analizar una muestra de sangre o de otra sustancia, para lo cual cuentan con medios científicos de extraordinaria utilidad y precisión.

Muy al contrario, los conceptos de imputabilidad/inimputabilidad y peligrosidad son mucho más sutiles, más circunstanciales, más inseguros.

Veamos la redacción del Art. 98:

El Juez o Tribunal podrá acordar el internamiento en un centro psiquiátrico del sujeto que haya sido declarado exento de responsabilidad criminal conforme al número $1^{\circ}$ del artículo 20 , o al que le haya sido apreciado esa eximente con carácter incompleto, si tras efectuarse una evaluación exhaustiva del mismo y de la acción que llevó a cabo, exista base suficiente para concluir que, debido a su trastorno, es posible prever la comisión por aquél de nuevos delitos y que, por tanto, supone un peligro para la sociedad. 
INFORMES

Resulta un tanto "hueca" la expresión

"Tras efectuarse una evaluación exhaustiva del mismo y de la acción que llevó a cabo"

A estas rotundas afirmaciones hay que aplicarles la cautela que encierra la siguiente batería de preguntas: ¿Cómo? ¿Cuándo? ¿Dónde? ¿Por quién?

Los que tenemos la experiencia en la práctica diaria sabemos que las evaluaciones en la mayoría de los casos no son, ni pueden ser "exhaustivas" y que a la postre, los conceptos complejos (el de peligrosidad lo es en alto grado) se llenan con "prejuicios" y resulta que la "peligrosidad del enfermo mental" lo es. Tiene mucho de mito, no soporta un análisis estadístico en relación a otros colectivos, pero está arraigada en los profesionales del Derecho y esto decide su suerte de modo que, en cuanto a juicio de peligrosidad, el enfermo mental entra en el proceso penal, ya derrotado.

Si el análisis de la peligrosidad (criterio de imposición de la medida) se presenta oscuro en el inicio del proceso, la situación no mejora en su desarrollo.

\section{5.- ANÁLISIS DE LOS ASPECTOS MÁS NEGATIVOS DEL PROYECTO}

Ya se ha dicho al comienzo de este comentario que el Proyecto ha mejorado algunos aspectos contenidos en el Anteproyecto pero, en cambio, no altera su filosofía de exclusión de la persona con trastorno mental o discapacidad intelectual, olvidando así los mandatos constitucionales de "rehabilitación", "reeducación" y "reinserción social", así como lo dispuesto en las Declaraciones y Tratados Internacionales en la materia, como la reciente Convención de la ONU sobre Derechos de las Personas con Discapacidad de 2006, ratificada por España en el año 2008.

Entre los aspectos más negativos del Proyecto, destacamos los siguientes:

1.- Excepciones al sistema vicarial

De acuerdo con el denominado "sistema vicarial", en caso de imposición conjunta de penas privativas de libertad y medidas de seguridad, la medida se ejecutará antes que la pena.

Así lo dispone el actual artículo 99 del C. Penal y así lo recoge el Art. 101-1 del Texto Proyectado.

Sin embargo el Proyecto introduce un segundo párrafo en este precepto que quiebra este sistema cuando la pena privativa impuesta supere los cinco años de prisión.

Dice así: 
INFORMES

Art. 100-2.

Si se hubieran impuesto al mismo tiempo una pena de más de cinco años de prisión y una medida de internamiento del artículo $100 \mathrm{del}$ Código Penal, el Juez o Tribunal podrán acordar que se cumpla en primer lugar una parte de la pena y seguidamente, la medida de seguridad. En este caso, la parte de la pena que debe ser cumplida en primer lugar se fijará de modo tal que, sumando el tiempo de duración de la medida de seguridad, se hayan extinguido dos terceras partes de la pena total impuesta.

De este modo, cuando se trate de hechos castigados con pena de cinco años de prisión, salta a primer plano el criterio "retribución" sin importar la situación o estado en que se encuentre el enfermo cuando es requerido para el cumplimiento de la pena.

Nuestra propuesta es que se elimine esta excepción y se mantenga el actual y vigente sistema vicarial contenido en el Art. 99 del C. Penal y Art. 101-1 del Texto Proyectado.

2.- Posibilidad de prolongación sucesiva de la medida de seguridad de internamiento

Dispone el Art. 98-3 del Proyecto

El internamiento en centro psiquiátrico no podrá tener una duración superior a cinco años, salvo que se acordare su prórroga.

$\mathrm{Si}$, transcurrido dicho plazo, no concurren las condiciones adecuadas para acordar la suspensión de la medida y, por el contrario, el internamiento continúa siendo necesario para evitar que el sujeto que sufre la anomalía o alteración psíquica cometa nuevos delitos a causa del mismo, el Juez o Tribunal a petición del Ministerio Fiscal, previa propuesta de la Junta de Tratamiento, podrá acordar, tras un procedimiento contradictorio en el que intervendrán el Ministerio Fiscal y el sometido a la medida, asistido por su Abogado, la prolongación de la medida por períodos sucesivos de cinco años.

Aunque, como se señaló al comienzo, esta posibilidad se somete en el Proyecto a un juicio contradictorio, resulta en sí misma:

* Contraria a la seguridad jurídica pues introduce la inconcreción de la duración de la medida que puede convertirse en perpetua.

* Discriminatoria, pues solo se aplica a las personas con trastorno mental o discapacidad intelectual. 
Nuestra propuesta es que se elimine la posibilidad de prolongación de la medida de internamiento, manteniendo la actual situación de equiparación penas/ medias contenida en el Art. 6-2 del C. Penal que dispone:

"Las medidas de seguridad no pueden resultar más gravosas ni de mayor duración que la pena abstractamente aplicable al hecho cometido, ni exceder del límite de lo necesario para prevenir la peligrosidad del autor”.

3.- Posibilidad de revocación de la suspensión de la ejecución de la medida de internamiento

El Juez de Vigilancia Penitenciaria puede suspender la ejecución de la medida de seguridad de internamiento si estima que ya no resulta necesaria.

Esta posibilidad se encuentra recogida en el Código Penal vigente (Art. 97) y en el Art. 102-1-c) del Proyecto.

Lo que ocurre es que el Proyecto va mucho más allá en este punto que el Código vigente. Así

3-1 La suspensión de la ejecución de la medida internamiento conllevará la imposición automática de la medida de libertad vigilada, con una duración máxima de cinco años.

Dispone el Art. 102-1 c:

1.- El Juez de Vigilancia Penitenciaria podrá, en cualquier momento durante la ejecución de la medida, verificar si se mantienen las circunstancias que hicieron necesaria su imposición y adoptar alguna de las siguientes resoluciones:

c) Suspender la ejecución de la medida. En este caso, se impondrá al sujeto una medida de libertad vigilada con una duración máxima de cinco años.

3-2 Se puede revocar la suspensión por circunstancias pasadas no conocidas - Art. 103- 2.

El Código vigente (Art. 97 d) contempla la posibilidad de revocación de la suspensión por comisión de nuevo delito dentro del plazo fijado, así como si nuevamente resultara acreditada la concurrencia de las circunstancias previstas en el Art. 95 (de las que pueda deducirse un comportamiento futuro que revele la probabilidad de comisión de nuevos delitos).

Esta posibilidad se sigue contemplando en el Proyecto en términos más estrictos.

Dispone el Art. 103-1:

1.- El Juez de Vigilancia Penitenciaria podrá revocar la suspensión de la ejecución de la medida privativa de libertad, cuando ello resulte necesario para asegurar los fines de la medida a la vista de la concu- 
INFORMES

rrencia de alguna de las siguientes circunstancias:

a) El sometido a la medida haya cometido un nuevo delito.

b) Incumpla gravemente las obligaciones y condiciones que hubieren sido impuestas en la libertad vigilada.

c) Incumpla reiteradamente su deber de comparecer y facilitar información al funcionario encargado del seguimiento del cumplimiento de la medida.

2.- También podrá acordarse la revocación de la suspensión ...., cuando se ponga de manifiesto un cambio de circunstancias que hubieran dado lugar a la suspensión que no permita mantener ya el pronóstico de falta de peligrosidad en que se fundaba la decisión adoptada.

Más allá de lo anterior, lo que verdaderamente resulta llamativo es que se contemple la posibilidad de revocación de la suspensión POR CIRCUNSTANCIAS PASADAS NO CONOCIDAS en el momento de otorgar la suspensión. Dispone el Art. 103-2:

2.- También podrá acordarse la revocación de la suspensión cuando se pongan de manifiesto circunstancias que habrían llevado a denegar la suspensión de la medida de haber sido conocidas en el momento en que ésta fue acordada

El Juez de Vigilancia Penitenciaria acordará la revocación de la suspensión a petición del Ministerio Fiscal, previa audiencia del sujeto a la medida, realizadas las comprobaciones y recabados los informes que resulten necesarios.

En todo caso, cuando existan razones de urgencia podrá ordenar, a petición del Ministerio Fiscal, la revocación inmediata de la suspensión. En estos casos, ratificará o reformará su decisión después de haber procedido conforme a lo dispuesto en el párrafo anterior.

Consideramos esta posibilidad como una extralimitación, no solo contraria a los más elementales principios del enjuiciamiento criminal, sino, además, incongruente dado que pretende justificar la revocación en hechos pasados, cuando lo relevante es realizar un juicio de futuro.

Nuestra propuesta es que la posible revocación de la suspensión se fundamente en hechos o circunstancias objetivas y sobrevenidas y que se elimine el Art. 103-2 que permite revocar la suspensión por circunstancias pasadas no conocidas. 
INFORMES

\section{4.- La libertad vigilada}

\section{4-1 Concepto}

La libertad vigilada no es una medida, como su nombre pudiera dar a entender, sino un conjunto de "obligaciones" de muy distinto carácter previstas en el Art. 104 bis del Proyecto que dispone:

1.- El Juez o Tribunal podrá imponer al sujeto sometido a la medida de libertad vigilada, durante todo el tiempo de duración de la misma o durante un período de tiempo determinado, el cumplimiento de las siguientes obligaciones y condiciones:

$1^{\mathrm{a}}$.- Prohibición de aproximarse a la víctima o a otros miembros de su familia que se determine por el Juez o Tribunal, a sus domicilios, a sus lugares de trabajo o a otros lugares habitualmente frecuentados por ellos. La imposición de esta prohibición será siempre comunicada a las personas con relación a las cuales sea acordada.

$2^{\mathrm{a}}$.- Prohibición de establecer contacto con personas determinadas o con miembros de un grupo determinado, cuando se trate de individuos de los que pueda sospecharse que pueden facilitarle la ocasión para cometer nuevos delitos o incitarle a hacerlo. También se le podrá prohibir establecer relación, ofrecer empleo, facilitar formación o albergar a cualquiera de las personas mencionadas.

$3^{\mathrm{a}}$.- Mantener su lugar de residencia en un lugar determinado con prohibición de abandonarlo sin autorización de los servicios de gestión de abandonarlo sin autorización de los servicios de gestión de penas y medidas alternativas.

$4^{\mathrm{a}}$.- Prohibición de residir en un lugar determinado o de acudir al mismo, cuando en ellos pueda encontrar la ocasión o motivo para cometer nuevos delitos.

$5^{\mathrm{a}}$.- Informar sin demora a los servicios de gestión de penas y medidas alternativas de sus cambios de residencia y de sus datos de localización. $6^{\mathrm{a}}$.- Comparecer personalmente con la periodicidad que se determine ante los servicios de gestión de penas y medidas alternativas o el servicio de la administración que se determine, para informar de sus actividades y justificarlas.

$7^{\mathrm{a}}$.- Participar en programas formativos, laborales, culturales, de educación vial, sexual, de defensa del medio ambiente, de protección de los animales, de igualdad de trato y no discriminación, y otros similares.

8 . - Participar en programas de deshabituación al consumo de drogas tóxicas o sustancias estupefacientes.

$9^{a}$.- Privación del derecho a conducir vehículos de motor o ciclomotores. 
INFORMES

$10^{\mathrm{a}}$.- Privación del derecho al porte o tenencia de armas.

$11^{a}$.-Prohibición de consumir alcohol, drogas tóxicas, sustancias estupefacientes o psicotrópicas, cuando existan razones que permitan suponer que aquél pueda incrementar el riesgo de comisión de nuevos delitos. En estos casos, se impondrá también el deber de someterse al control de consumo de esas sustancias con la periodicidad que se determine o cuando se considere oportuno por los servicios de gestión de penas y medidas alternativas.

$12^{\mathrm{a}}$.- Inscribirse en las oficinas de empleo.

$13^{\mathrm{a}}$.- Someterse a tratamiento ambulatorio. En este caso se determinarán las fechas o la periodicidad con que el sometido a la medida debe presentarse ante un médico, psiquiatra o psicólogo.

$14^{\mathrm{a}}$.- Someterse a custodia familiar o residencial. En este caso, el sujeto a la medida será puesto bajo el cuidado y vigilancia de una persona o institución que a tal fin se designe y que acepte el encargo de custodia. El ejercicio de la custodia comprenderá la obligación de informar al servicio competente de la administración penitenciaria sobre la situación del custodiado, con una periodicidad al menos mensual. La información será inmediata de periodicidad al menos mensual. La información será inmediata de sustraerse a la vigilancia o control.

$15^{\mathrm{a}}$.- Llevar consigo y mantener en adecuado estado de conservación los dispositivos electrónicos que hubieran sido dispuestos para controlar los horarios en que acude a su lugar de residencia o, cuando resulte necesario, a los lugares en que se encuentra en determinados momentos o el cumplimiento de alguna de las medidas a que se refieren las reglas $1^{\text {a }}$ a $4^{\mathrm{a}}$. Esta regla solamente podrá ser impuesta cuando el sujeto hubiera sido condenado por alguno de los delitos a que se refieren las letras a) y f) del número 1 del artículo 101.1 de este Código.

16.- Prohibición de conducir vehículos a motor que no dispongan de dispositivos electrónicos que condicionen su encendido a la comprobación previa de las condiciones psicofísicas del conductor, cuando el sujeto haya sido condenado por un delito contra la seguridad vial y la medida resulte necesaria para prevenir la comisión de nuevos delitos.

$17^{\mathrm{a}}$.- Cumplir los demás deberes que el Juez o Tribunal estime convenientes para la rehabilitación social del penado, previa conformidad de éste, siempre que no atenten contra su dignidad como persona.

2.- El Juez o Tribunal podrán también imponer, durante todo el tiempo de duración de la medida o durante un período de tiempo determinado, el cumplimiento de otras obligaciones y condiciones, especialmente aquéllas que se refieren a la formación, trabajo, ocio, o desarrollo de su actividad habitual. 
INFORMES

3.- No podrán imponerse deberes y obligaciones que resulten excesivos y desproporcionados con las circunstancias del caso.

\section{4-2 Finalidad}

Eliminada en el Proyecto, la medida de "custodia de seguridad" que contenía el Anteproyecto, la medida de "libertad vigilada" se alza en el nuevo texto como guardián y recurso último para neutralizar la "peligrosidad" del enfermo.

\section{4-3 Duración}

El Art. 104 ter 1 y 3 establecen:

1.- La libertad vigilada tendrá una duración mínima de tres años y una duración máxima de cinco.

\section{4-4 Requisitos para su imposición}

El Art. 104 establece

1.- El Juez o Tribunal impondrán una medida de libertad vigilada cuando se cumplan los siguientes requisitos:

a) La imposición de la medida de libertad vigilada esté prevista en la Ley penal para el delito cometido.

b) Se haya impuesto al sujeto una pena de más de un año de prisión.

c) Se cumplan los requisitos de los números 2 y 3 del artículo 95.1 del Código Penal.

2.- Asimismo, se impondrá una medida de libertad vigilada:

a) Cuando haya sido absuelto por haber sido apreciada la concurrencia de alguna de las eximentes de los números $1^{\circ}, 2^{\circ}$ ó $3^{\circ}$ del artículo 20 de este Código, o haya sido apreciada la atenuante $1^{\text {a }}$ del artículo 21 con relación a alguna de las anteriores, y se cumplan los demás requisitos del artículo 95.1 del mismo.

b) Cuando se haya acordado el cese de una medida de seguridad privativa de libertad.

Consideramos que los requisitos para su imposición son muy livianos. En cuanto al límite objetivo de la pena impuesta no resulta proporcionado que la condena a pena de un año y un día de prisión pueda dar lugar a la imposición de libertad vigilada de hasta cinco años (prorrogables)

Se propone que el Art. 104-1 b) se modifique en el sentido de exigir la condena a pena de más de tres años de prisión. 
INFORMES

Consideramos que no es procedente la imposición "automática" de libertad vigilada en los supuestos de que se aprecie un eximente completa o incompleta o al cese de una medida de seguridad privativa de libertad.

Se propone la modificación del Art. 104-2 en el sentido de eliminar el término "impondrá" y sustituirlo "podrá imponer" si los informes técnicos que se recaben avalan la necesidad de la medida.

A nuestro juicio se hace un uso abusivo e irracional de la misma por las siguientes razones:

1.- Se puede imponer por diversas vías

* 1-1 Al cesar la medida de internamiento - Art. 98-3 in fine y 104-2 b

"Extinguida la medida de internamiento impuesta, se impondrá al sujeto una medida de libertad vigilada, salvo que la misma no resultara necesaria".

La regla general es que tras la extinción de la medida de internamiento se imponga una medida de libertad vigilada.

* 1-2 Al suspenderse la medida de seguridad - Art. 102-1 c

1.- El Juez de Vigilancia Penitenciaria podrá, en cualquier momento durante la ejecución de la medida, verificar si se mantienen las circunstancias que hicieron necesaria su medida, verificar si se mantienen las circunstancias que hicieron necesaria su imposición y adoptar alguna de las siguientes resoluciones:

c) Suspender la ejecución de la medida. En este caso, se impondrá al sujeto una medida de libertad vigilada con una duración máxima de cinco años.

2. Se puede decretar el internamiento (preventivo) para no revocar la medida de libertad vigilada - Art. 103 bis 1

1.- Si durante el cumplimiento de una medida de libertad vigilada que hubiera sido impuesta al suspenderse la ejecución de una medida de internamiento en centro psiquiátrico se pusiera de manifiesto un empeoramiento grave en la salud mental de la persona sujeta a la medida, el Juez o Tribunal podrán acordar, con la finalidad de evitar una revocación de la medida, su internamiento en un centro psiquiátrico por un plazo máximo de tres meses que podrá ser prorrogado por tres meses más.

Estimamos que si durante el cumplimiento de la libertad vigilada, la persona sufre un empeoramiento grave en su salud mental deberá ser objeto de atención y, en su caso, de ingreso civil. Lo que a nuestro juicio resulta inadecuado es la revocación de la libertad y retorno al centro psiquiátrico. Las posibilidades de abordar la situación creada por el empeoramiento son múltiples y no necesariamente han de pasar por el reingreso en centro psiquiátrico. 
3- Se puede prorrogar-Art. 104 ter 2.

2.- El plazo máximo de duración (de la libertad vigilada) podrá ser prorrogado por plazos sucesivos de una duración máxima de cinco años cada uno de ellos, cuando se hubieran producido anteriormente incumplimientos relevantes de las obligaciones y condiciones impuestas conforme al artículo 104 bis de los que puedan derivarse indicios que evidencien un riesgo relevante de comisión futura de nuevos delitos, y además:

a) La medida de libertad vigilada hubiera sido impuesta en los supuestos del artículo 192.1 de este Código, o,

b) de conformidad con lo dispuesto en la letra c) del artículo 102.1 de este Código.

Se propone la eliminación de la posibilidad de prorrogar la libertad vigilada por basarse en apreciaciones subjetivas y difusas contrarias al principio de seguridad jurídica.

\section{6.- OTRAS CUESTIONES A TENER EN CUENTA}

\section{1.- ASPECTOS PROCESALES - LA TRAMPA DE LOS JUICIOS RÁPIDOS}

La reforma no tiene en cuenta la realidad diaria de los procedimientos ni lo que en ellos ocurre con gran generalidad.

Hoy, buena parte del enjuiciamiento penal y de los hechos cometidos por personas con trastorno mental grave, se realiza a través de los denominados "juicios rápidos".

En este procedimiento es posible obtener una sentencia firme a las pocas horas de sucedido el hecho, siempre que el sujeto admita que lo que ha cometido y se conforme con la pena que le solicite la acusación, pena que, en atención a esta circunstancia, le será rebajada por el Juez en un tercio, en la sentencia que inmediatamente se dictará.

a) Son tan veloces los trámites que, en muchos casos es difícil reparar en que la persona imputada padece un trastorno mental, de modo que no se toma en cuenta esta circunstancia.

Al tratarse de un supuesto de "enajenación inadvertida" se aplica al sujeto la normativa prevista para las personas imputables, con imposición de las penas correspondientes sin posibilidad de aplicar medida de seguridad alguna.

b) En algunos casos sí se detecta la existencia de una anomalía o trastorno mental.

En estos casos lo procedente sería poner fin al enjuiciamiento "rápido" y 
INFORMES

encauzar el asunto a través del enjuiciamiento ordinario.

Sin embargo en la práctica esto no es frecuente.

Las hipótesis que pueden darse son variadas.

* Conformidad con la aplicación de una eximente completa o incompleta con imposición de medida de seguridad de internamiento

* Conformidad con aplicación de una mera atenuante

* No conformidad con la pena o medida solicitada por la acusación lo que conlleva el señalamiento de juicio a celebrar en un plazo de quince días.

Lo que queremos poner de relieve es que, en los primeros casos (conformidad), el juicio de "inimputabilidad" plena o parcial no puede ser en modo alguno "exhaustivo". A lo sumo se pondrá contar con un somero examen por el Médico Forense.

En el tercer caso (no conformidad), existe un breve plazo de tiempo para que el Letrado de la persona con anomalía o trastorno mental pueda obtener pruebas destinadas a demostrar la inimputabilidad total o parcial del sujeto.

Esto será factible en relación con documentos o certificados médicos que el sujeto tuviese en su poder. En cambio, resultará mucho más difícil conseguir que en tan breve periodo de tiempos pueda ser examinado por un especialista y que éste acuda a juicio a explicar su informe.

A la postre, la consecuencia evidente de todo esto es que cuando se imponen penas privativas de libertad de cumplimento efectivo, los enfermos las cumplen en Centros Penitenciarios Ordinarios, donde se detecta con facilidad su presencia.

Como ya hemos señalado, estimamos que lo procedente cuando se detecta en el Juzgado de Guardia la presencia de una anomalía o trastorno mental, sería poner fin al enjuiciamiento "rápido" y encauzar el asunto a través del enjuiciamiento ordinario.

2.- ASPECTOS CONCEPTUALES - CONSECUENCIAS PENITENCIARIAS DE LA CORRECTA APLICACIÓN DEL CONCEPTO DE IMPUTABILIDAD

Aún cuando se detecte la presencia en el sujeto de una anomalía o trastorno y mental y se encauce el asunto por el procedimiento ordinario, (lo que permite realizar una investigación sosegada y completa, sin sujeción a plazos), no se acaban los problemas.

Ocurre que el concepto de imputabilidad adoptado por Código Penal desde el año 1995 (que no se modifica en el Proyecto de Reforma) busca establecer, con indudable criterio científico, la relación de la enfermedad con el "delito concreto" en el "momento concreto" de su comisión.

Ocurre que, si la investigación pone de relieve que en ese momento y/o para ese delito la persona con anomalía o trastorno mental grave "era imputable", no se aplicará eximente ni atenuante alguna ni, por tanto, se podrá tampoco imponer ninguna medida de seguridad. 
INFORMES

Desde el punto de vista científico el planteamiento es impecable pero tiene como consecuencia perversa que conduce a las prisiones ordinarias a muchas personas con discapacidad o trastorno mental porque a la cárcel no se puede mandar sólo la parte de la persona que pudo cometer un hecho que le es imputable, sino a la persona entera.

Creemos adecuado proponer que, aún en estos casos, si bien no sería de aplicación la rebaja de la pena por razones de inimputabilidad, sí debería tomarse en cuenta esta circunstancia en la sentencia y habilitar el Juez para imponer la/s medida/ de seguridad que se consideren oportunas.

\section{7 - SOBRE LA MEDIDA DE SEGURIDAD DE SUMISIÓN A TRATAMIENTO AMBULATORIO}

Esta medida que, con distintos nombres, ha contemplado el Código Penal desde hace décadas, ha resultado viable cuando ha contado con la aceptación del enfermo.

En otro caso ha devenido en un completo fracaso.

Por esta razón, la reforma del Código Penal realizada en virtud de L.O. 5/2010 de 22 de Junio, sometió las medidas relativas a tratamientos médicos, al consentimiento del enfermo quien, podía incluso poner fin a un tratamiento ya iniciado.

Establece el actual Art. 100-3 del C. Penal:

No se considerará quebrantamiento de la medida la negativa del sujeto a someterse a tratamiento médico o a continuar un tratamiento médico inicialmente consentido. No obstante, el Juez o Tribunal podrá acordar la sustitución del tratamiento inicial o posteriormente rechazado por otra medida de entre las aplicables al supuesto de que se trate.

En definitiva se respeta el derecho de autodeterminación en relación con los tratamientos de salud mental, aún en el ámbito penal.

El Anteproyecto mantiene la medida (dentro de la órbita de la libertad vigilada) Artículo 104 bis

1.- El Juez o Tribunal podrá imponer al sujeto sometido a la medida de libertad vigilada, durante todo el tiempo de duración de la misma o durante un período de tiempo determinado, el cumplimiento de las siguientes obligaciones y condiciones: 
INFORMES

$13^{\mathrm{a}}$.- Someterse a tratamiento ambulatorio. En este caso se determinarán las fechas o la periodicidad con que el sometido a la medida debe presentarse ante un médico, psiquiatra o psicólogo.

Lo que desaparece en el Proyecto es un precepto similar al Art. 100-3, esto es, la necesidad de contar con el consentimiento del enfermo.

Se puede decir, sin temor a equivocación, que resultará un completo fracaso el tratar de imponer esta medida por la fuerza.

Proponemos que la sumisión a tratamiento ambulatorio solo pueda imponerse contando con el consentimiento del enfermo.

Debemos añadir que, de manera cíclica, aparecen propuestas de regulación del los tratamientos ambulatorios forzosos DE CARÁCTER CIVIL.

Hasta ahora la propuesta ha sido debatida y rechazada en las dos ocasiones que ha sido planteada ante el Parlamento del Estado (2004 y 2007) y también por el Parlamento de Cataluña (2010).

La AEN ha fijado ya su posición en cuatro informes a los que nos remitimos, el último de los cuales titulado "El tratamiento ambulatorio involuntario: historia de una obstinación" (2011).

Sobre los argumentos esgrimidos en sede parlamentaria se puede consultar:

* El Diario de Sesiones del Congreso de los Diputados del día 5 de Octubre de 2004 (Pleno) - Toma en consideración de la propuesta de FEAFES.

* El Diario de Sesiones del Congreso de los Diputados - (Comisión de Justicia) - Días 1 y 2 de Marzo de 2005 - Comparecencia de Expertos sobre propuesta de FEAFES.

* El Diario de Sesiones del Congreso de los Diputados - (Comisión de Justicia) - Día 17 de Mayo de 2007 - Comparecencias de Expertos sobre propuesta de regulación del Tratamiento Ambulatorio Involuntario en la Ley de Jurisdicción Voluntaria.

* El Diario de Sesiones del Parlamento de Cataluña sobre reaparición en el año 2010 en el Proyecto de Ley del Libro II del Código Civil $\left(212-2-5^{\circ}\right)$ de la propuesta de judicialización de los tratamientos ambulatorios involuntarios.

Compartimos el comentario realizado por FEAFES (Confederación Española de Agrupaciones de Familiares y Personas con Enfermedad Mental) al Proyecto de Reforma del Código Penal en lo tocante a la libertad vigilada que dice:

"Si por ventura, la persona lograra recuperar su libertad, extinguiéndose la medida de seguridad, podrá ser sometida a una medida de libertad vigilada (Arts. 98, 102 y ss...).

No hay mención alguna a la atención comunitaria o acompañamiento para lograr una efectiva inclusión en la sociedad con el máximo 
nivel posible de salud mental como alternativa para la prevención de hechos delictivos.

Al contrario, el nuevo Art. 104 bis, permitirá al Juez o Tribunal imponerle durante todo el tiempo de duración de la medida o durante un periodo de tiempo determinado, el cumplimiento de una serie de obligaciones y condiciones, entre las que se cuenta la establecida en el apartado 13: "Someterse a tratamiento ambulatorio"

Esta disposición, sin contar con el consentimiento de una persona que, además, no habrá recibido hasta la fecha la atención y cuidados que precisaba y que es más que probable que salga desprovista de apoyos y acompañamiento, está claro que está abocada al fracaso.

FEAFES le pregunta entonces al legislador: ¿A que quedan reducidos los valores constitucionales de resocialización y de salvaguarda de la igualdad real y efectiva.

Cabe destacar además la incoherencia de que este Proyecto incluya el Tratamiento Ambulatorio conforme el Tribunal Constitucional dispuso que ha de estar regulado por una Ley Orgánica aún inexistente. FEAFES reivindica la eliminación del Tratamiento Ambulatorio figurando en su lugar el Tratamiento Comunitario adecuado e integral de probada efectividad para el tratamiento de las personas con trastorno mental grave".

Proponemos que se incluya entre las medidas de libertad vigilada "los Equipos de Atención Domiciliaria y Seguimiento en la Comunidad, individualizados"

8.- POSIBILIDAD DE IMPUGNACIÓN DEL CÓDIGO PENAL ANTE TRIBUNALES INTERNACIONALES, COMUNITARIOS, COMITÉ SE SEGUIMIENTO DE LA CONVENCIÓN DE LA ONU SOBRE DERECHOS DE LAS PERSONAS CON DISCAPACIDAD, ETC...

Consideramos que muchas de las medidas y disposiciones contenidas en el Proyecto referidas a las Personas con Discapacidad o Trastorno Mental Grave, contravienen lo proclamado en la Convención de la ONU de 2006 sobre Derechos de las Personas con Discapacidad (Arts 5, 12, 14, 15, 17, 19, 25 y 26) en la medida que suponen un tratamiento discriminatorio, desproporcionado y, por tanto, injusto

El Estado Español, que fue uno de los primeros firmante de la Convención ya ha sido examinado por el Comité de seguimiento del cumplimiento de la misma (Septiembre de 2011). 
INFORMES

En relación con el derecho a la libertad y seguridad de la persona (Art. 14 de la Convención) realiza la siguiente recomendación:

El Comité recomienda al Estado parte que revise sus disposiciones legislativas que autorizan la privación de libertad por motivos de discapacidad, incluidas las discapacidades mentales, psicológicas o intelectuales; que derogue las disposiciones que autorizan el internamiento forzoso a causa de una incapacidad manifiesta o diagnosticada, y que adopte medidas para que los servicios médicos, incluyendo todos los servicios relacionados con la salud mental, se basen en el consentimiento otorgado con conocimiento de causa por el interesado.

La Unión Europea ha sido firmante también de la Convención.

Su trasgresión podrá ser denunciada ante los Tribunales y Organismos Internacionales competentes.

\section{9.- LA PREVENCIÓN Y ATENCIÓN COMUNITARIA}

La Constitución de 1978 proclama que los Poderes Públicos garantizan la asistencia sanitaria y social para todos los ciudadanos y, de un modo especial, para las personas con discapacidad (Art. 49). Pero la realidad es otra.

Es verdad que existe en España una buena red de recursos sociosanitarios para el ciudadano medio, pero apenas se ha desarrollado respecto de determinadas discapacidades, ni para las personas con trastorno mental grave que presentan resistencia a seguir control y tratamiento médico.

Así las cosas, compartimos y reiteramos la ya expuesta reivindicación de FEAFES (máximo nivel posible de recursos de salud mental, como alternativa para la prevención de hechos delictivos).

\section{0.- CONCLUSIONES}

1.- Es preciso reconocer que el Proyecto que ahora vamos a analizar, elimina alguno de los aspectos más negativos que contenía el Anteproyecto, como la medida de "custodia de seguridad" y somete a mayores garantías de contradicción decisiones tan trascendentes y, en nuestra opinión, discriminatorias, como la posibilidad de prorrogar el internamiento por periodos sucesivos de cinco años (Art. 98-3 II). 
2.- Resulta muy grave la mutación de un "derecho penal del hecho" en "derecho penal de autor".

La peligrosidad no es un concepto clínico ni psicopatológico. No hay fundamento científico para que los profesionales de la salud mental puedan evaluar la presunta peligrosidad de la persona.

El "derecho penal del hecho" exige contextualizar las conductas, analizar el hecho delictivo en sus circunstancias y extraer de tal análisis los motivos y las eventuales consecuencias.

El "derecho penal de autor" permite descontextualizar las conductas, vinculándolas a las características personales del sujeto. El trastorno mental vuelve desde el campo sanitario al jurídico-penal, ya que, antes que enfermedad, es vuelto a considerar peligro o amenaza.

3.- Resulta preocupante la apelación al concepto genérico de peligrosidad, lo que puede repercutir de modo muy negativo en la respuesta penal frente a hechos cometidos por personas con anomalía o trastorno mental debido a la pervivencia (muy arraigada en el ámbito judicial) del estigma que acompaña a estos trastornos.

El Estado podría muy bien prevenir estas situaciones mediante la implantación de un eficaz sistema de intervención sociosanitaria, con una red de servicios de atención en salud mental ya previstos en el Art. 20 de la Ley General de Sanidad del año 1986 y desarrollada en posteriores textos (Ley 16/2003 de 28 de Mayo de cohesión y calidad del Sistema Nacional de Salud - R.D. 1030/2006 de 15 de Septiembre de cartera de servicios comunes del Sistema Nacional de Salud - Estrategia en Salud Mental del Sistema Nacional de Salud - 2006 - ) cuya implantación resulta aún muy escasa.

Se reivindica de modo especial, la necesidad de disponer de Equipos de Atención Domiciliaria, Enfermería, Tratamientos Asertivos Comunitarios, PSI (en Cataluña), etc..., que puedan con celeridad y accesibilidad, dar una Atención Intensiva a la crisis, allí donde se genere.

A ello habría que añadir una importante modificación del marco conceptual de las políticas de atención en salud mental y un incremento de la sensibilidad respecto de los problemas de este colectivo tan vulnerable.

4.- No se advierte en la sociedad un cambio de actitud, en relación con la situación existente al promulgarse el Código Penal de 1995, que justifique la incorporación al Código Penal de medidas tan alejadas de los fines rehabilitadores y reinsertadores previstos en el Art. 25-2 en relación con el Art. 9-2 de la Constitución Española.

5.- El Proyecto no toma en cuenta la carencia de medios actual para evaluar conceptos tan complejos como "imputabilidad" y "peligrosidad".

6.- El Proyecto no toma en cuenta la realidad de los "juicios rápidos" donde 
INFORMES

resulta difícil advertir la presencia de "trastornos" o "anomalías psíquicas" y, en ningún caso, realizar un examen exhaustivo al respecto.

7.- Debería aprovecharse la reforma para impedir que las cuestiones relativas a la Imputabilidad y peligrosidad se examinen en el marco de los denominados "Juicios Rápidos"

8.- Debería aprovecharse la reforma para permitir que frente a hechos "imputables" cometidos por personas con anomalía o trastorno mental, pudiera tenerse en cuenta esta circunstancia en orden a la posibilidad de imponer medidas de seguridad.

9.- Ante todo ello, la AEN quiere hacer llegar su gran preocupación por los efectos hostiles y, nuevamente estigmatizantes, que el anteproyecto de modificación del Código Penal puede suponer para las personas que sufren un trastorno mental. Su aprobación significaría un retroceso, en garantías y derechos conseguidos a partir de la Constitución y sucesivas modificaciones legislativas (Código Penal, Código Civil, Ley de Enjuiciamiento Civil), en las que la AEN participó de modo muy activo.

\section{1.- ENMIENDAS}

1.- Supresión del Art. 100-2 del Proyecto pues supone una excepción injustificada a la aplicación del denominado "sistema vicarial" (cumplimiento de la medida de seguridad antes que la pena privativa de libertad, en caso de concurrencia de ambas).

Proponemos que se mantenga la aplicación del sistema vicarial en todos los casos, tal y como se contempla en el Art. 99 del Código Penal actualmente vigente.

2.- Supresión del Art. 98-3 del Proyecto que permite prorrogar la medida de seguridad de internamiento por periodos sucesivos de cinco años.

Proponemos que se mantenga la equiparación en cuanto a su duración de penas y medidas en los términos previstos en el Art. 6-2 del Código Penal actualmente vigente.

3.- Supresión del Art. 103-2 que permite revocar la suspensión de la ejecución en virtud de circunstancias pasadas no conocidas en el momento de la concesión de la suspensión.

4.- Modificación del Art. 104-1 b) en el sentido de exigir la condena a pena de más de tres años de prisión como requisito para la imposición de libertad vigilada. 
5.- Modificación del Art. 104-2 en el sentido de eliminar el término "impondrá" y sustituirlo por el término "podrá imponer" si los informes técnicos que se recaben avalan la imposición de la medida.

6.- Supresión del Art. 103-bis-1 dado que las posibilidades de abordar la situación creada por el empeoramiento en el estado de salud mental del enfermo son múltiples y no necesariamente han de pasar por el reingreso en centro psiquiátrico.

7.- Supresión del Art. 104-Ter-2 que permite prorrogar la libertad vigilada por periodos sucesivos de cinco años por basarse tal decisión en apreciaciones subjetivas y difusas, contrarias al principio de seguridad jurídica.

8.- Inclusión en el Art. 104 bis - 13a , que, en todos los casos, la sumisión a tratamiento ambulatorio ha de contar con el consentimiento del enfermo.

9.- Inclusión entre las medidas de libertad vigilada, los programas de Tratamiento Asertivo Comunitario con seguimiento individualizado a cargo de los equipos o dispositivos de salud mental a los que el enfermo esté adscrito.

Grupo de "Ética y Legislación." Asociación Española de Neuropsiquiatría (AEN)

Noviembre 2013 